\title{
Report
}

\section{Off-pump Surgical Removal of Right Atrial Myxoma Without Hypothermia}

\section{Yury Shevchenko, Gleb Borshchev}

Federal State Budgetary Institution "National Medical and Surgical Center Named After N. I. Pirogov" of the Ministry of Healthcare of the Russian Federation, Moscow, Russia

Email address:

glebcenter@mail.ru (G. Borshchev)

\section{To cite this article:}

Yury Shevchenko, Gleb Borshchev. Off-pump Surgical Removal of Right Atrial Myxoma Without Hypothermia. International Journal of Cardiovascular and Thoracic Surgery. Vol. 6, No. 6, 2020, pp. 75-78. doi: 10.11648/j.ijcts.20200606.13

Received: November 20, 2020; Accepted: December 2, 2020; Published: December 16, 2020

\begin{abstract}
Myxoma of the right atrium is a rare heart tumor. Atrial myxomas are associated with a triad of complications, including obstruction, emboli, and constitutional symptoms (such as fever, weight loss). An interdisciplinary approach is very important to optimize the outcome in patients with atrial myxomas. When myxoma present, it can rarely cause blood flow obstruction in the right cardiac chamber. $75 \%$ to $80 \%$ are located on the left side of the interatrial septum. Right-sided cardiac myxomas present surgeons a lot of technical difficult. We report a case of right atrial myxoma. A 75-year-old female with a large right atrial myxoma underwent surgical treatment in our Center. Due to the high risk of embolic complications associated with conventional connection of a cardiopulmonary bypass machine, we decided to preform beating-heart surgery with clamping of major vessels (aorta, pulmonary artery, and venae cavae). This technique is a method of avoiding embolization. The early postoperative period was uneventful. Two days postoperatively, the patient was transferred from the intensive care unit to hospital ward. Nine days postoperatively, she was discharged in satisfactory condition to continue her follow-up at a local outpatient department. The patient was followed up during the next 3 years and had no signs of relapse.
\end{abstract}

Keywords: Heart Neoplasms/Surgery, Myxoma, Cardiac, Myxoma, Surgery, Off-pump

\section{Background}

Cardiac tumors are exceedingly rare and their early diagnosis is difficult. Such patients usually have poor prognosis, while the treatment strategy is ambiguous [1, 2]. The most common formations in the heart include thrombi, tumors, and foreign bodies [2]. The incidence of cardiac neoplasms does not exceed $0.2 \%$. Myxoma is the most common cardiac tumor. It is usually located in the left atrium [3]. The prevalence of right atrial myxomas was evaluated in studies conducted by Mayo Clinic. Forty-one out of 23,673 patients $(0.17 \%)$ were found to have cardiac tumors at autopsy (1954-1979). Myxomas were detected in 28 patients; of them, only 4 tumors (14\%) were located in the right atrium \%) [4-6].

Since it is morphologically benign, cardiac myxoma has a malignant course: there is a high probability of obstruction (including sudden obstruction) of the heart valves and major vessels, tumor fragmentation with subsequent embolism [2]. If the tumor is infected, the patient develops clinical manifestations of infective endocarditis with a high risk of sepsis.

\section{Case Presentation}

We report a case of myxoma in a 75-year-old female patient. She was admitted to the Pirogov Center with complaints of pressing pain behind the sternum after minor physical exercises disappearing at rest, shortness of breath, fatigue, arrhythmia, and increased blood pressure (up to 180/100 $\mathrm{mmHg})$.

In accordance to her disease history, in April 2016 she developed cough and fever $\left(38^{\circ} \mathrm{C}\right)$, was diagnosed with pneumonia, and was treated in a local hospital with a short-term positive effect. She was discharged after that.

On 25.07.2016, she developed pain in the hypochondrium, epigastric area, and pasty shins. She was admitted to the 
pulmonary department of a local hospital, where she was found to have pulmonary embolism and infarction-pneumonia. Echocardiography revealed a tumor in the right atrium. The patient was transferred to the Pirogov Center for examination and treatment. We should mention that the time between the diagnosis and admission to a specialized hospital was more than 1 month.

\section{Results of Physical, Laboratory, and Instrumental Examination}

Upon admission, the patient was in satisfactory condition. Transesophageal echocardiography demonstrated a large formation occupying almost entire volume of the right atrium. This formation created a hemodynamically significant obstacle for blood flow (Figure 1).
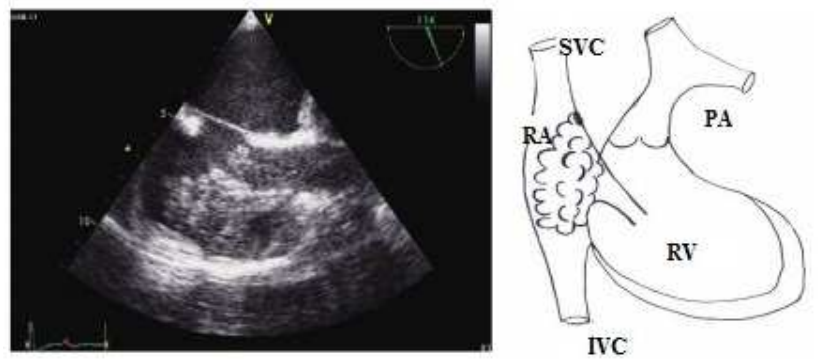

Figure 1. Transesophageal echocardiography of the patient, scheme.

Preliminary clinical diagnosis: formation in the right atrium of unknown etiology. Complications: pulmonary embolism, infarction pneumonia (in July 2011), grade IIA circulatory insufficiency.

The only possible treatment option was cardiac surgery, which is usually performed with artificial circulation. However, cardiopulmonary bypass (and especially cannulation of venae cavae via the right atrium) was associated with a high risk of embolic complications caused by damage to the tumor during cannulation of venae cavae and the inability to completely remove the tumor.

Therefore, the patient required open-heart surgery without cardiopulmonary bypass. Pirogov Center has a unique experience in such operations, including removal of bullets and fragments in patients with gunshot wounds to the heart and removal of infected electrodes of the artificial cardiac pacemaker from the right atrium. We decided to perform beating-heart surgery.

\section{Treatment}

The patient underwent beating-heart surgery without cardiopulmonary bypass: removal of the myxoma from the right atrium

The heart was approached via longitudinal median sternotomy. The pericardium was opened. Inspection of the pericardial cavity demonstrated enlarged right chambers. The venae cavae, aorta, and pulmonary trunk were isolated using tourniquets (Figure 2).

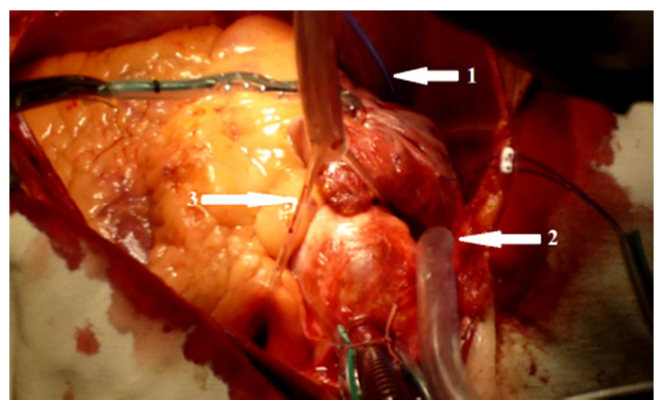

Figure 2. Heart with tourniquets placed on it. Arrows: 1 - tourniquet on the inferior vena cava, 2 -tourniquet on the superior vena cava, 3-tourniquet on the aorta and pulmonary trunk.

We performed sequential clamping of the inferior vena cava, superior vena cave (after several cardiac cycles), and then aorta and pulmonary trunk (after another several cardiac cycles) (Figure 3).

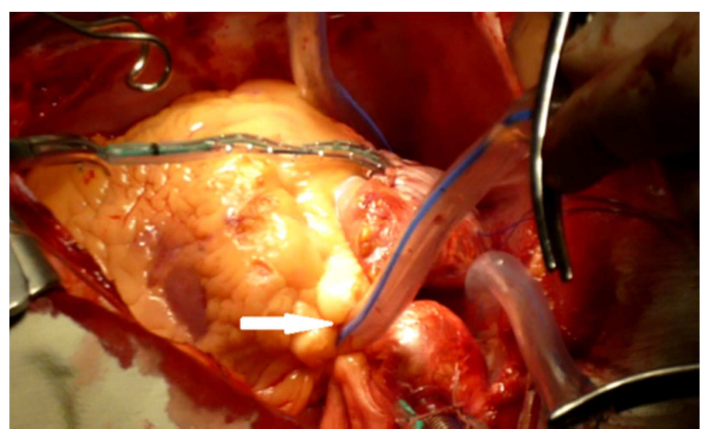

Figure 3. Heart with tourniquets placed on it (clamping). Arrows indicate clamped aorta and pulmonary artery.

A 50-mL jelly-like transparent yellow formation (myxoma) was found in the right atrium (Figure 4).

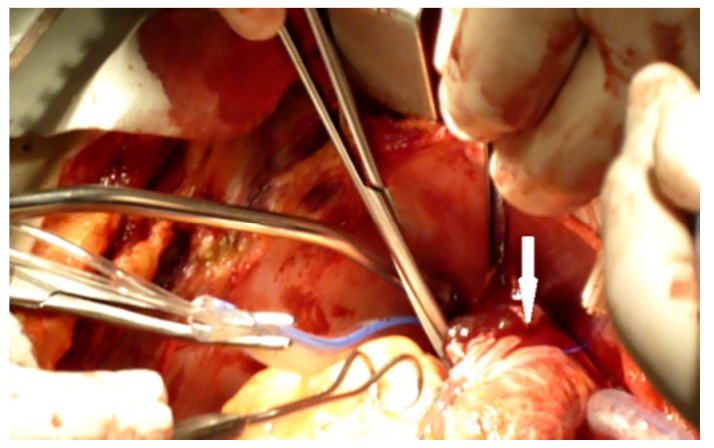

Figure 4. Opened right atrium. The arrow indicates the myxoma.

Using tweezers, special spoon, and vacuum pump, the tumor was removed as a single block. To prevent recurrence of myxoma, we excised its pedicle located at the junction of the superior vena cava and the interatrial septum, considering the proximity of the conduction system. Diathermocoagulation was used at the site of pedicle attachment. 


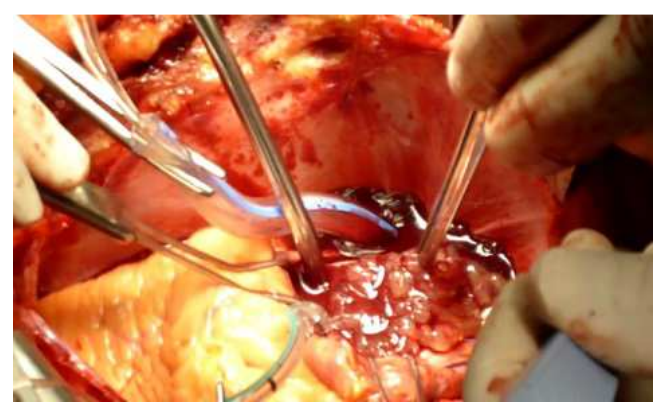

Figure 5. Stage of myxoma removal.

We took all necessary measures to prevent air embolism. Then we sequentially removed the tourniquets from the inferior vena cava (along with tightening of the purse-string suture around the right atrium), superior vena cava, aorta, and pulmonary trunk. The intracardiac stage of the operation lasted $150 \mathrm{~s}$.

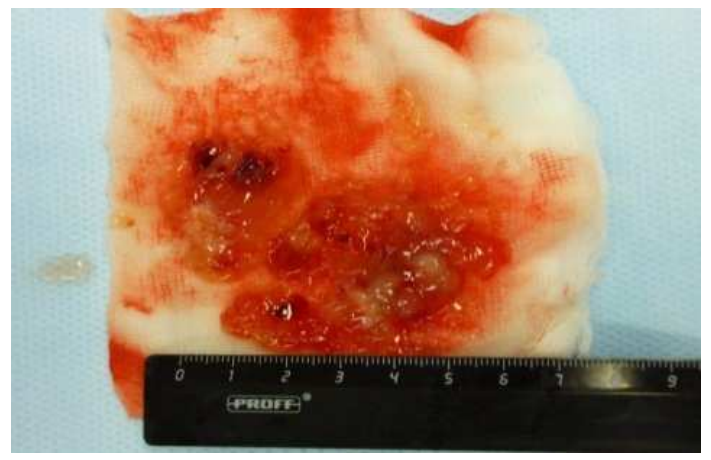

Figure 6. Gross examination of the removed myxoma.

The early postoperative period was uneventful. Two days postoperatively, the patient was transferred from the intensive care unit to hospital ward. Nine days postoperatively, she was discharged in satisfactory condition to continue her follow-up at a local outpatient department.

Outcome and Follow-up

The patient was followed up during the next 3 years and had no signs of relapse.

\section{Discussion}

The right atrial myxoma accounts for only $10-15 \%$ of all cardiac myxomas. Atypical localizations of myxoma are most often found in cases of familial myxoma [8]. Our patient had no history of relatives suffering from this disease.

The complexity of the right atrial myxoma is the possibility of its destruction [9, 10] during connection of a cardiopulmonary bypass machine [11-15]. Due to the high risk of embolic complications, we did beating-heart surgery with clamping of major vessels (aorta, pulmonary artery, and venae cavae).

\section{Conclusion}

Thus, we utilized our extensive experience in beating-heart surgeries and performed the first successful removal of the right atrial myxoma without cardiopulmonary bypass and hypothermia.

\section{Additional Information}

\section{Patient's Concent}

The patient signed an informed consent for the publication of her medical data stripped of personal identifiers in the Journal 'International Journal of Cardiovascular and Thoracic Surgery'

\section{Competing Interests}

The authors declare no conflict of interest related to this manuscript.

\section{References}

[1] Reynen K. Frequency of primary tumors of the heart. Am J Cardiol. 1996; 77.

[2] Neragi-Miandoab S, Kim J, Vlahakes GJ. Malignant tumours of the heart: a review of tumour type, diagnosis and therapy. Clin Oncol (R Coll Radiol) 2007; 19: 748-756.

[3] Imperio, J, Summers D, Krasnow N, Piccone VA Jr. The distribution patterns of biatrial myxomas. Ann Thorac Surg 1980; 29: 469-73.

[4] Hoffmeier A, Sindermann JR, Scheld HH, Martens S. Cardiac tumors-diagnosis and surgical treatment. Dtsch Arztebl Int. 2014; 111 (12): 205-211. doi: 10.3238/arztebl.2014.0205.

[5] Fyke FE 3rd. Transesophageal echocardiography and cardiac masses. Mayo Clin Proc. 1991 Nov; 66 (11): 1171-4. PubMed PMID: 1943251.

[6] Pinede L, Duhaut P, Loire R. Clinical presentation of left atrial cardiac myxoma. A series of 112 consecutive cases. Medicine. 2001; 80: 159-172.

[7] Oliveira R, Branco L, Galrinho A, et al. Cardiac myxoma: a 13-year experience in echocardiographic diagnosis. Rev Port Cardiol. 2010; 29: 1087-1100.

[8] McCarthy PM, Piehler JM, Schaff HV, Pluth JR, Orszulak TA, Vidaillet HJ Jr, Carney JA. The significance of multiple, recurrent, and "complex" cardiac myxomas. J Thorac Cardiovasc Surg. 1986 Mar; 91 (3): 389-96. PMID: 3951243.

[9] Latifi AN, Ibe U, Gnanaraj J. A case report of atrial myxoma presenting with systemic embolization and myocardial infarction. Eur Heart J Case Rep. 2019 Jul 11; 3 (3): ytz104. doi: 10.1093/ehjcr/ytz104. PMID: 31660480; PMCID: PMC6764541.

[10] Matsuoka S, Ito M, Shinonome T, Yoshitoshi M, Tanimura A. [An autopsy case of cerebral embolism caused by atrial myxoma]. No Shinkei Geka. 1992 Mar; 20 (3): 255-9. Japanese. PMID: 1557175.

[11] Michiel P. van der Zee, Bart M. Koene, Massimo A. Mariani, Fatal air embolism during cardiopulmonary bypass: analysis of an incident and prevention measures, Interactive Cardio Vascular and Thoracic Surgery, Volume 19, Issue 5, November 2014, Pages 875-877, https://doi.org/10.1093/icvts/ivu242. 
[12] Neema PK, Pathak S, Varma PK, Manikandan S, Rathod RC, Tempe DK, Tung A. Case 2--2007: Systemic air embolization after termination of cardiopulmonary bypass. J Cardiothorac Vasc Anesth. 2007 Apr; 21 (2): 288-97. doi: 10.1053/j.jvca.2006.09.012. Epub 2007 Jan 9. PMID 17418752 .

[13] DeFoe GR, Dame NA, Farrell MS, Ross CS, Langner CW, Likosky DS. Embolic activity during in vivo cardiopulmonary bypass. J Extra Corpor Technol. 2014; 46 (2): 150-156.

[14] Taylor RL, Borger MA, Weisel RD, Fedorko L, Feindel CM. Cerebral microemboli during cardiopulmonary bypass: Increased emboli during perfusionist interventions. Ann Thorac Surg. 1999; 68: 89-93.

[15] Blauth CI. Macroemboli and microemboli during cardiopulmonary bypass. Ann Thorac Surg. 1995 May; 59 (5): 1300-3. doi: 10.1016/0003-4975(95)00105-t. PMID: 7733756.

\section{Biography}

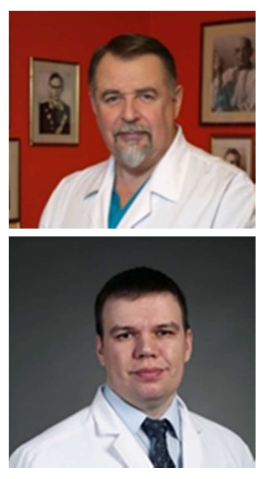

Yury Shevchenko, Academician of the Russian Academy of Sciences, MD, PhD, DSc, President of the N. I. Pirogov National Medical and Surgical Center (Moscow) (ORCID ID 0000-0001-7473-7572).

Gleb Borshchev, MD, PhD, Associate Professor in the Department of Chest and cardiovascular Surgery with the Course of $\mathrm{X}$-ray-guided Endovascular Surgery, Institute of Postgraduate Education, N. I. Pirogov National Medical and Surgical Center (Moscow) (ORCID ID 0000-0002-8332-7521). 